\title{
Impacts of heat and mass flux on MHD flow and heat transfer of radiative nanofluid past an exponentially shrinking/stretching sheet with viscous and Ohmic dissipations
}

\author{
M. DINESH KUMAR ${ }^{1}$ and M. THIAGARAJAN ${ }^{2}$ \\ Department of Mathematics 1,2 \\ PSG College of Arts \& Science ${ }^{1,2}$ \\ Coimbatore - 641014, Tamilnadu, \\ INDIA.
}

\begin{abstract}
The present correspondence is conveyed to analyze the influence of heat flux and mass flux on magnetohydrodynamic (MHD) and heat transfer flow of radiative nanofluid past an exponentially shrinking/stretching porous sheet with viscous dissipation and Ohmic heating. Heat transfer characteristics with heat generation, thermophoresis, Brownian motion and also chemical reaction effects are addressed. To simulation the equations of momentum, energy and nanoparticle concentration, appropriate similarity transformation variables is employed. These transformed ordinary differential equations are solved numerically using the Nachtsheim-Swigert shooting technique scheme together with fourth order Runge-Kutta method. The effects of several parameters on the dimensionless velocity, temperature and concentration profiles are presented graphically. This study discloses that the variable heat and mass fluxes have important impacts on the temperature profile and concentration. We have found that solutions exist in both shrinking and stretching cases. It is remarked that the presence of radiation, Brownian motion, heat generation and magnetic interaction parameter enhances the temperature and reduces the concentration profile.
\end{abstract}

Key-Words: - Nanofluid; MHD; radiation; viscous dissipation; Ohmic heating; exponentially shrinking/stretching sheet; heat flux; mass flux

Received: March 2, 2020. Revised: September 7, 2020. Accepted: September 30, 2020.

Published: October 23, 2020.

\section{Introduction}

The heat transfer occurrence in boundary layer flow past a stretching/shrinking sheet is too important for its day by day increasing industrial applications. These procedures are paper and fiber manufacture, cooling metallic sheets, crystal growing, materials manufactured by extrusion, etc. The flow due to linearly stretching sheet was first discovered by Crane [1]. Kumaran and Ramanaiah [2] presented the viscous incompressible flow past a stretching surface. Cortell [3] investigated the heat transfer and viscous flow over a stretching surface by numerically. In recent decades, the studies concentrated on exponentially and nonlinearly stretching sheet were exhibited here. The twodimensional nonlinear problem of mixed convection flow of a micropolar fluid has been investigated by Hayat et al. [4]. Kishan et al. [5] employed the hydromagnetic boundary layer flow of a radiative nanofluid past an exponentially permeable stretching sheet with heat source/sink effects by numerically. In recent days, the boundary layer flow with convective heat transfer due to shrinking sheet has attracted considerable interest. After few years, Stagnation point flow past a shrinking sheet was analyzed by Wang [6]. The heat and mass transfer on a stretching/shrinking sheet becomes additional exciting when the warmth flux and mass flux conditions on the boundary are taken into consideration. In heat transfer technology, the heat flux occurrence plays a critical part in controlling the rate of heat transfer. Later, Fang [7] explored the boundary layers past a continuously shrinking sheet with power-law velocity by numerically. Bhattacharya [8] discussed about heat transfer and boundary layer flow over an exponentially shrinking sheet. Jisoh et al. [9] examined the problem of 
magnetohydrodynamic flow of water based nanofluids over a bidirectional exponential shrinking/stretching sheet.

Orthodox liquids have poor thermal conductivity resulting in limited applications in engineering areas. It is a fundamentally homogeneous mixture of base fluids and nanoparticles. This lack of fluids was taken into account by [10] and these developed nanofluids. The nanofluid is an excellent candidate in designing the waste heat removal system during the emergency core cooling system was proved by Buongiorno and $\mathrm{Hu}$ [11]. Nanofluids have many new attributes that make them so much dependable in heat transfer processes, such as microelectronics, composite-powered engines, and engine cooling energy management [12]. Dehghani et al. [13] studied the magnetohydrodynamic flow of a nanofluid mixed convection in a grooved channel with internal heat generation effect.

The study of hydromagnetic (or) magnetohydrodynamic (MHD) flows have given raise to many industrial and engineering problems like procedure of cooling of nuclear reactor, electronic package, solar technology, blood flow measurements and MHD pumps, etc. MHD viscous flow and heat transfer adjacent to a shrinking sheet was examined analytically by Noor et al. [14]. An attempt was made by Lok et al. [15] investigated the two-dimensional MHD stagnation-point flow past a shrinking sheet with suction. Nayak et al. [16] examined the effect of electrically conducting threedimensional nature convective flow of radiative nanofluid past a linear stretching sheet. Thiagarajan and Dinesh Kumar [17] discussed the influence of heat generation on MHD flow of radiative nanofluid over an exponentially stretching surface in the presence of viscous dissipation.

When the assessment of the convection heat transfer factor is unimportant, thermal radiation significantly impacts the total surface heat transfer. Influences of radiation and viscous dissipation on boundary layer flow past a stretching surface was analyzed by Cortell [18]. Many authors discussed some fruitful studies for radiative nanofluids. The study of viscous dissipation yields a significant enhance in fluid temperature. In these dissipation changes the temperature profiles by played a role liking an energy generation. Few very latest efforts in this direction has made been in the scrutinizes.
Ohmic heating is a growing technology with large number of factual and future applications. It includes sterilization, fermentation, and military field etc. Some recent investigates featuring ohmic heating may be found [19]. Awais et al. [20] studied heat generation/absorption effects in a nonNewtonian fluid flow over a stretching sheet. Very Recently, Combined effects of viscous-ohmic dissipation and heat source/sink on hydromagnetic flow of nanofluid past a stretching sheet were investigated by Mishra and Manojkumar [21]. Thumma et al. [22] discussed the heat generation and dissipation effects of three dimensional MHD flow and casson radiative nanofluid over a stretching sheet.

Motivated by all the above investigations limited their study on both shrinking and stretching type by considering heat and mass fluxes with dissipation effects. In this present study, our main aim to investigate the problem of steady, two-dimensional heat and mass flux on hydromagnetic flow and heat transfer of a nanofluid over an exponential shrinking/stretching porous sheet. Rosseland approximation is employed for the thermal radiation contribution. The system is transformed into ordinary differential equations and has been solved numerically. The numerical solutions are portrayed graphically for the tested parameters are magnetic interaction parameter, permeability, Prandtl number, thermal radiation, Brownian motion, thermophoresis, Eckert number, heat generation, chemical reaction, Lewis number and suction parameter. Solutions exist in both shrinking and stretching cases for the physical problem.

\section{Problem Formulation}

We consider the steady, laminar, viscous, incompressible hydromagnetic flow of radiative nanofluid past an exponentially shrinking/stretching surface in the presence of heat and mass fluxes. Heat generation, chemical reaction, thermophoresis, and Brownian motion impacts in current flow are taken into account. The shrinking/stretching velocity $U_{w}(x)=\delta c e^{x / L}$ is presumed to differ from the origin $O$, where $c$ is a positive constant $(c>0)$ and $L$ is a length and it varies linearly from origin, where $y=0$ as shown in Figure 1 (a) and (b).

The simplified two-dimensional boundary layer equations that governing the present flow subject to the Boussinesq approximations can be expressed as follows: 
The equation of continuity is

$$
\frac{\partial u}{\partial x}+\frac{\partial v}{\partial y}=0
$$

The momentum equation is

$\rho_{f}\left(u \frac{\partial u}{\partial x}+v \frac{\partial u}{\partial y}\right)=\mu_{f} \frac{\partial^{2} u}{\partial y^{2}}-\sigma B^{2}(x) u-\mu_{f} \frac{u}{k_{1}}$

The energy equation is

$$
\begin{array}{r}
u \frac{\partial T}{\partial x}+v \frac{\partial T}{\partial y}=\alpha_{f} \frac{\partial^{2} T}{\partial y^{2}}-\frac{1}{\left(\rho C_{p}\right)_{f}} \frac{\partial q_{r d}}{\partial y}+\frac{\mu_{f}}{\left(\rho C_{p}\right)_{f}}\left(\frac{\partial u}{\partial y}\right)^{2}+ \\
\frac{Q^{*}(x)}{\left(\rho C_{p}\right)_{f}}\left(T-T_{\infty}\right)+\frac{\sigma B^{2}(x) u^{2}}{\left(\rho C_{p}\right)_{f}}+ \\
\tau\left(D_{B} \frac{\partial C}{\partial y^{2}} \frac{\partial T}{\partial y}+\frac{D_{T}}{T_{\infty}}\left(\frac{\partial T}{\partial y}\right)^{2}\right)
\end{array}
$$

The mass equation is

$u \frac{\partial C}{\partial x}+v \frac{\partial C}{\partial y}=D_{B} \frac{\partial^{2} C}{\partial y^{2}}+\frac{D_{T}}{T_{\infty}} \frac{\partial^{2} T}{\partial y^{2}}-K_{r}\left(C-C_{\infty}\right)$

where $u$ and $v$ are the velocity components in the $x$ and $y$ direction, respectively, $\rho_{f}$ is the density of the base fluid, $\mu_{f}$ is the dynamic viscosity, $\sigma$ is the electrical conductivity, $k_{1}$ is the porous media permeability, $T$ is the fluid temperature, $C$ is the nanoparticle volume fraction, $\alpha_{f}$ is the thermal diffusivity, $\tau=\frac{(\rho C)_{p}}{(\rho C)_{f}}$ is the ratio between the effective heat capacity of the nanoparticle material and heat capacity of the base fluid, $D_{B}$ is the Brownian diffusion coefficient, $D_{T}$ is the thermophoresis diffusion coefficient, and $K_{r}$ is the rate of chemical reaction. Also, $Q^{*}(x)$ is the variable heat generation parameter, and $B(x)$ is the variable magnetic field parameter are considered as

$Q^{*}(x)=Q_{0} e^{\frac{x}{L}}, \quad$ and $B(x)=B_{0} e^{\frac{x}{2 L}}$,

The respective boundary conditions for the flow analysis are

$$
\begin{aligned}
& u=U_{w}(x), v=-V_{w}(x), \\
& \frac{\partial T}{\partial y}=-\frac{q_{w}(x)}{\alpha}, \frac{\partial C}{\partial y}=-\frac{q_{n p t}(x)}{D_{B}} \text { at } y=0, \\
& u \rightarrow 0, \quad T \rightarrow T_{\infty}, C \rightarrow C_{\infty} \quad \text { as } y \rightarrow \infty
\end{aligned}
$$

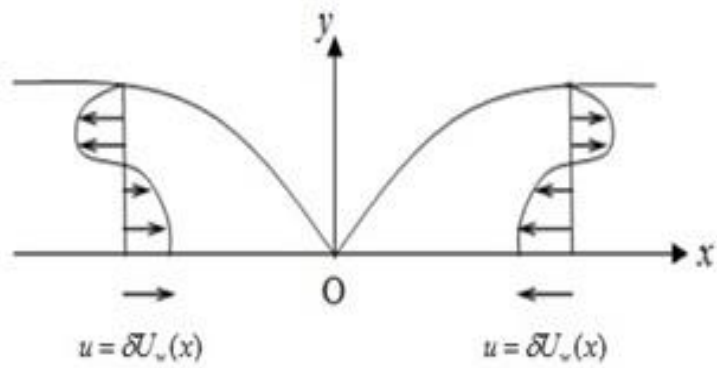

(a) Shrinking case $(\delta<0)$

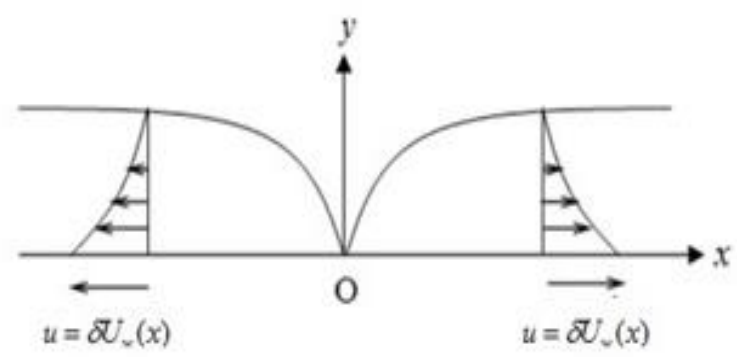

(b) Stretching case $(\delta>0)$

Fig. 1 Flow of the Geometry [both (a) \& (b)]

where $U_{w}(x)=\delta c e^{\frac{x}{L}}$ is the shrinking/stretching velocity (for $\delta<0$ is shrinking and $\delta>0$ is stretching), $\quad V_{w}(x)=V_{0} e^{\frac{x}{2 L}}$ is the variable mass transfer velocity (for $V_{0}<0$ is mass suction and $V_{0}>0$ is mass injection), $q_{w}(x)=q_{w_{0}} T_{0}\left(\frac{c}{2 v L}\right)^{\frac{1}{2}} e^{x / L}$ is the variable surface heat flux, and $q_{n p t}(x)=q_{n p t_{0}} C_{0}\left(\frac{c}{2 v L}\right)^{\frac{1}{2}} e^{x / L}$ is the variable surface mass (nanoparticle) flux.

Using Rosseland estimation for heat radiation (Hossain et al. [23]), has the form,

$q_{r d}=-\frac{4 \sigma^{*}}{3 k^{*}} \frac{\partial T^{4}}{\partial y}$

where $k^{*}$ is the mean absorption coefficient and $\sigma^{*}$ is the Stefan-Boltzman constan. The temperature difference within the flow is such that $T^{4}$ may be enlarged in a Taylor sequences about $T_{\infty}$ and neglecting higher order terms, we obtain

$T^{4} \cong 4 T_{\infty}^{3}-3 T_{\infty}^{4}$

Therefore, the Eq. (3) becomes, 


$$
\begin{aligned}
& u \frac{\partial T}{\partial x}+v \frac{\partial T}{\partial y}= \alpha_{f} \frac{\partial^{2} T}{\partial y^{2}}-\frac{1}{\left(\rho C_{p}\right)_{f}} \frac{16 \sigma T_{\infty}^{3}}{3 k^{*}} \frac{\partial^{2} T}{\partial y^{2}}+ \\
& \frac{\mu_{f}}{\left(\rho C_{p}\right)_{f}}\left(\frac{\partial u}{\partial y}\right)^{2}+\frac{Q^{*}(x)}{\left(\rho C_{p}\right)_{f}}\left(T-T_{\infty}\right)+ \\
& \frac{\sigma B^{2}(x) u^{2}}{\left(\rho C_{p}\right)_{f}}+\tau\left(D_{B} \frac{\partial C}{\partial y^{2}} \frac{\partial T}{\partial y}+\frac{D_{T}}{T_{\infty}}\left(\frac{\partial T}{\partial y}\right)^{2}\right)
\end{aligned}
$$

The mass Equ. (1) is fulfilled by introducing a stream function $\psi(x, y)$ such that

$$
u=\frac{\partial \psi}{\partial y}, \quad v=-\frac{\partial \psi}{\partial x}
$$

We look for a unifications solution of the above boundary value problem; therefore, we introduce the following similarity transformation variables

$$
\begin{aligned}
& \psi=(2 v L c)^{1 / 2} f(\eta) e^{\frac{x}{2 L}} ; \\
& \eta=y\left(\frac{c}{2 v L}\right)^{1 / 2} e^{\frac{x}{2 L}} ; \\
& u=c e^{\frac{x}{L}} f^{\prime}(\eta) ; \\
& v=-\left(\frac{c v}{2 L}\right)^{1 / 2} e^{x / 2 L}\left\{f(\eta)+\eta f^{\prime}(\eta)\right\} ; \\
& T=T_{\infty}+\frac{q_{w_{0}}}{\alpha} T_{0} e^{x / 2 L} \theta(\eta) ; \\
& C=C_{\infty}+\frac{q_{n p t_{0}}}{D_{B}} C_{0} e^{x / 2 L} h(\eta)
\end{aligned}
$$

Committed to the transformed dimensionless of the form

$$
\begin{aligned}
& f_{\eta \eta \eta}+f f_{\eta \eta}-2 f_{\eta}^{2}-M f_{\eta}-K_{p} f_{\eta}=0 \\
& \frac{1}{\operatorname{Pr}}\left(1+\frac{4 R_{d}}{3}\right) \theta_{\eta \eta}+f \theta_{\eta}-f_{\eta} \theta+E c f_{\eta \eta}^{2}+E c M f_{\eta}^{2}+ \\
& N b \theta_{\eta} h_{\eta}+N t \theta_{\eta}{ }^{2}+Q_{h} \theta=0
\end{aligned}
$$

$h_{\eta \eta}+L e f h_{\eta}-L e f_{\eta} h-L e C_{r} h+\left(\frac{N t}{N b}\right) \theta_{\eta \eta}=0$

and the boundary conditions Eq. (6) become

$$
\begin{aligned}
& f(0)=f_{w}, f^{\prime}(0)=\delta, \theta^{\prime}(0)=-1, h^{\prime}(0)=-1 \quad \text { at } \eta=0 \\
& f^{\prime}(\eta) \rightarrow 0, \theta(\eta) \rightarrow 0, h(\eta) \rightarrow 0 \quad \text { as } \eta \rightarrow \infty
\end{aligned}
$$

where $M$ is the magnetic interaction parameter, $K_{p}$ permeability parameter, $\mathrm{Pr}$ is the Prandtl number, $R_{d}$ is the thermal radiation parameter, $E c$ is the Eckert number, $\mathrm{Nb}$ is the Brownian motion parameter, $N t$ is the thermophoresis parameter, $Q_{h}$ is the heat generation parameter, $L e$ is the Lewis number, $C_{r}$ is the chemical reaction parameter, and $f_{w}$ is the suction parameter $\left(f_{w}>0\right.$, ie. $\left.V_{0}<0\right)$. They are respectively defining as,

$$
\begin{aligned}
M & =\frac{2 \sigma B_{0}^{2} L}{c \rho_{f}}, \quad K_{p}=\frac{v L}{c k_{1}}, \quad \operatorname{Pr}=\frac{v}{\alpha}, \quad R_{d}=\frac{4 \sigma^{*} T_{\infty}^{3}}{k^{*} k_{n f}}, \\
E c & =\frac{c^{2} e^{2 x / L}}{\left(C_{p}\right)_{f}\left(T_{w}-T_{\infty}\right)}, C_{r}=\frac{2 K_{r} L}{c} \\
N b & =\frac{(\rho C)_{p}}{(\rho C)_{f}} \frac{C_{0} q_{n p t_{0}}}{v}, N t=\frac{(\rho C)_{p} D_{T}}{(\rho C)_{f} T_{\infty}} \frac{T_{0} q_{w_{0}}}{v \alpha}, \\
Q_{h} & =\frac{2 L Q^{*}}{\left(\rho C_{p}\right)_{f} c}, L e=\frac{v}{D_{B}}, f_{w}=\frac{V_{0}}{\sqrt{v c / 2 L}}
\end{aligned}
$$

The local skin friction coefficient $C_{f}$, local nusselt number $N u_{x}$, and Sherwood number $S h_{x}$ which are defined as

$$
\begin{aligned}
& C_{f}=\left.\frac{v}{U_{w}^{2} \rho_{f}} \frac{\partial u}{\partial y}\right|_{y=0}, N u_{x}=-\left.\frac{x}{\left(T-T_{\infty}\right)} \frac{\partial T}{\partial y}\right|_{y=0}, \\
& S h_{x}=-\left.\frac{x}{\left(C-C_{\infty}\right)} \frac{\partial C}{\partial y}\right|_{y=0}
\end{aligned}
$$

Therefore,

$\sqrt{2 \operatorname{Re}_{x}} C_{f}=f^{\prime \prime}(0)$,

$\frac{N u}{\sqrt{2 \mathrm{Re}_{x}}}=-\sqrt{\frac{x}{2 L}} \theta^{\prime}(0)$,

$\frac{S h}{\sqrt{2 \mathrm{Re}_{x}}}=-\sqrt{\frac{x}{2 L}} g^{\prime}(0)$

where $\operatorname{Re}_{x}=\frac{U_{w} x}{v}$ is the local Reynolds number.

\section{Method of Solution of the Problem}

The governing nonlinear partial differential equations are converted to nonlinear ordinary differential equations by similarity variables with the necessary similarity variables. The equations (12), (13), and (14) represent a highly nonlinear boundary value problem of third and second order, which is arduous to solve analytically. Then the equations are solved numerically using the most efficient shooting technique such as the Nachtsheim-Swigert shooting iteration technique for satisfaction of asymptotic boundary conditions 
along with Runge-Kutta fourth-order based integration method with step size $h=0.01$. The numerical values of non-dimensional velocity, temperature, and concentration are obtained for different values of physical parameters. The level of the accuracy for convergence is taken upto $10^{-5}$.

\section{Results and Discussion}

Numerical values as displayed graphically employing figures for dimensionless velocity, temperature distribution, and concentration profile for various set of values suction parameter $f_{w}$, magnetic interaction parameter $M$, permeability parameter $K_{p}$, Prandtl number Pr, thermal radiation parameter $R_{d}$, Eckert number $E c$, Brownian motion parameter $N b$, thermophoresis parameter $N t$, heat generation parameter $Q_{h}$, chemical reaction parameter $C_{r}$, and Lewis number Le.

Figure 2 exhibits the influence of suction parameter $f_{w}$ on dimensionless velocity profiles for shrinking/stretching cases respectively. It is noted that enhance in suction parameter $\left(f_{w}=3.0,3.5\right.$, and 4.0) accelerates the velocity profiles of the fluid in shrinking $(\delta=-1)$ but it takes opposite action in stretching $(\delta=1)$.

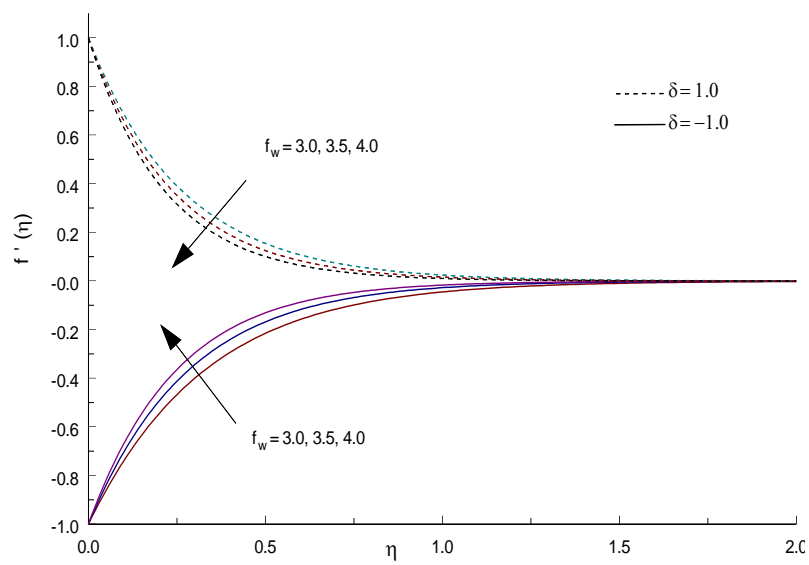

Fig. 2 The velocity profiles $f^{\prime}(\eta)$ with $\eta$ for several values of $f_{w}$.

Figure 3 presents the dimensionless temperature for variable suction parameter $f_{w}$. It is reported that the temperature decelerated with increasing suction parameter. Also, the impact of suction parameter $f_{w}$ is to enhance the heat transfer from the sheet to the ambient fluid. Figure 4 plotted to illustrate the impact of suction parameter $f_{w}$ on concentration profile for shrinking/stretching case. It is seen that the concentration profile diminishes with the increase of suction parameter $f_{w}$.

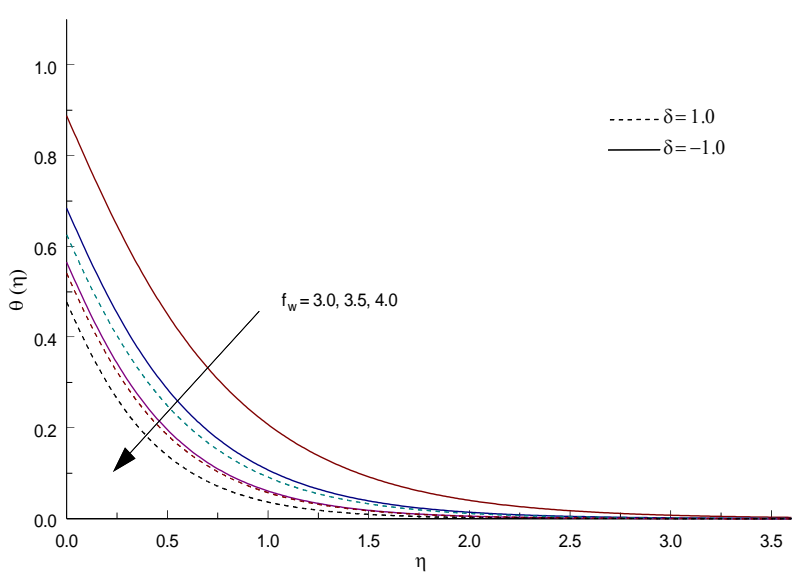

Fig. 3 Temperature distribution $\theta(\eta)$ with $\eta$ for several values of $f_{w}$.

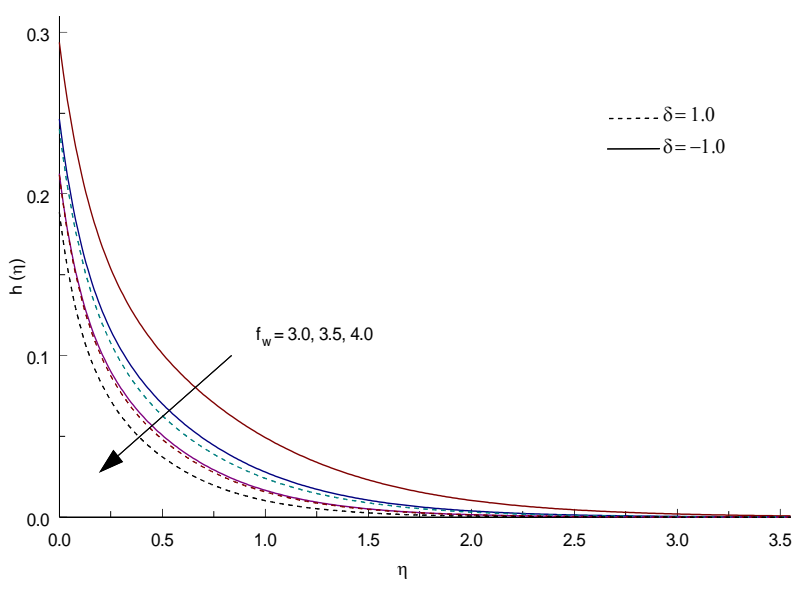

Fig. 4 Variation of concentration $h(\eta)$ with $\eta$ for several values of $f_{w}$.

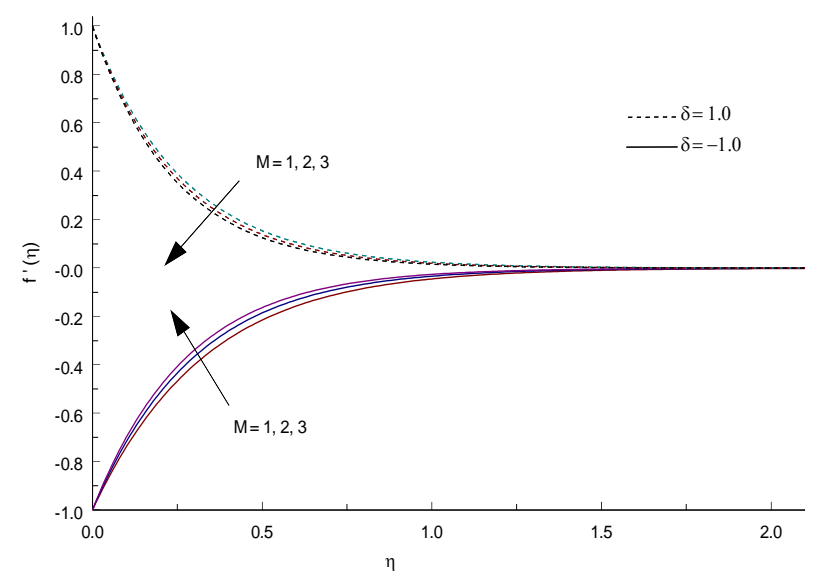

Fig. 5 The velocity profiles $f^{\prime}(\eta)$ with $\eta$ for several values of $M$. 
Variation of velocity $f^{\prime}(\eta)$ due to the impact of magnetic interaction parameter $M$ with shrinking/stretching surface, are portrayed in Figure 5 . It is regarded that the velocity profile decelerates with enhancing magnetic interaction parameter $M$ for when $\delta=1$ (stretching case) and velocity profile rises with increases magnetic interaction parameter $M$ for when $\delta=-1$ (shrinking case).

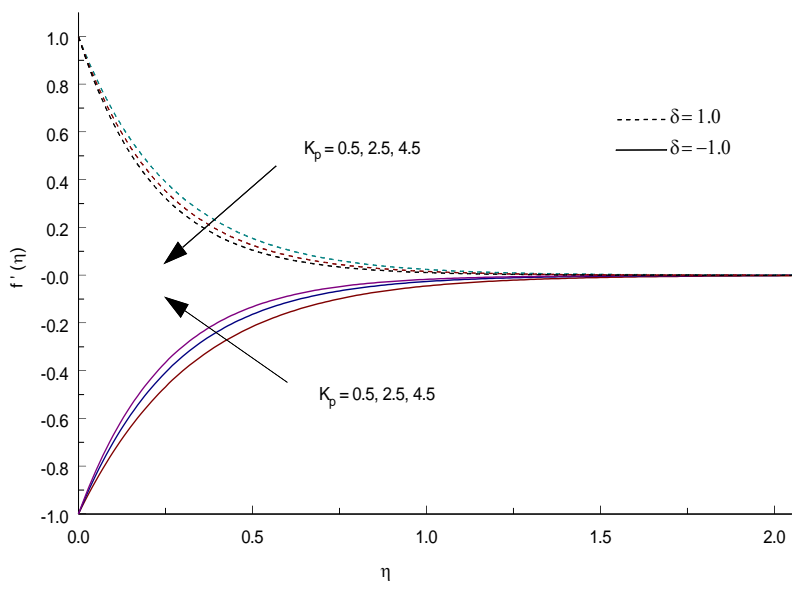

Fig. 6 The velocity profiles $f^{\prime}(\eta)$ with $\eta$ for several values of $K_{p}$.

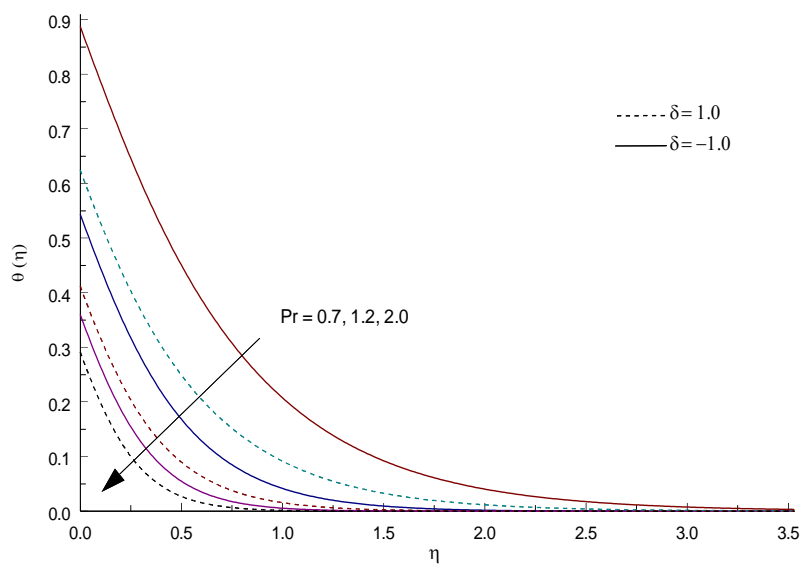

Fig. 7 Temperature distribution $\theta(\eta)$ with $\eta$ for several values of $\mathrm{Pr}$.

Figure 6 are plotted to displays the impact of permeability parameter $K_{p}$ affects the dimensionless velocity of the fluid. It is inferred that an increase in permeability parameter $K_{p}$ reduces the velocity profile for stretching case and permeability parameter $K_{p}$ increases with increasing velocity profile for shrinking case. Also, we regarded that the presence of porous medium causes high level limitation to the fluid.

The good selection of Prandtl number $\operatorname{Pr}$ is significant in heat transfer studies. Figure 7 demonstrates temperature distribution $\theta(\eta)$ versus various values of Prandtl number Pr. It is inferred that the temperature distribution and thermal boundary layer thickness are reducing with increasing Prandtl number for both the cases of shrinking/stretching sheet. Also, Prandtl number Pr increases significantly with the decreases in thermal conductivity of the fluid.

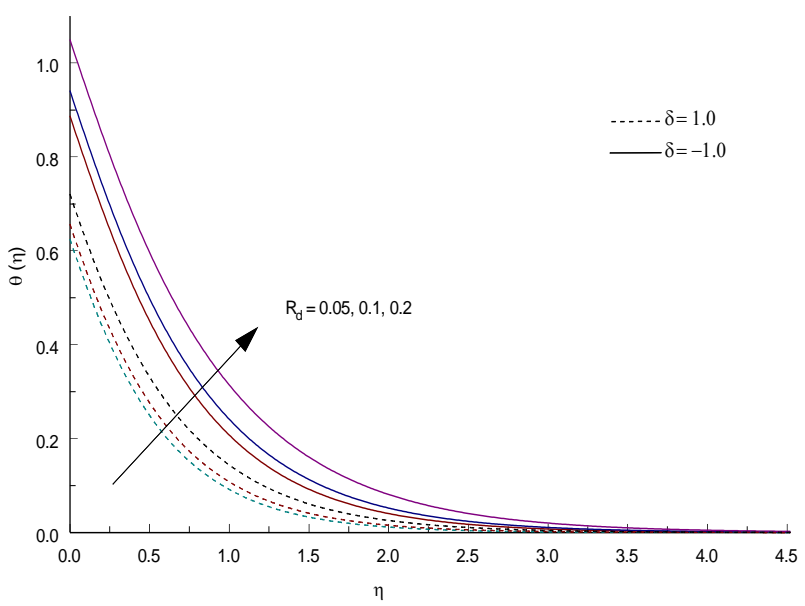

Fig. 8 Temperature distribution $\theta(\eta)$ with $\eta$ for several values of $R_{d}$.

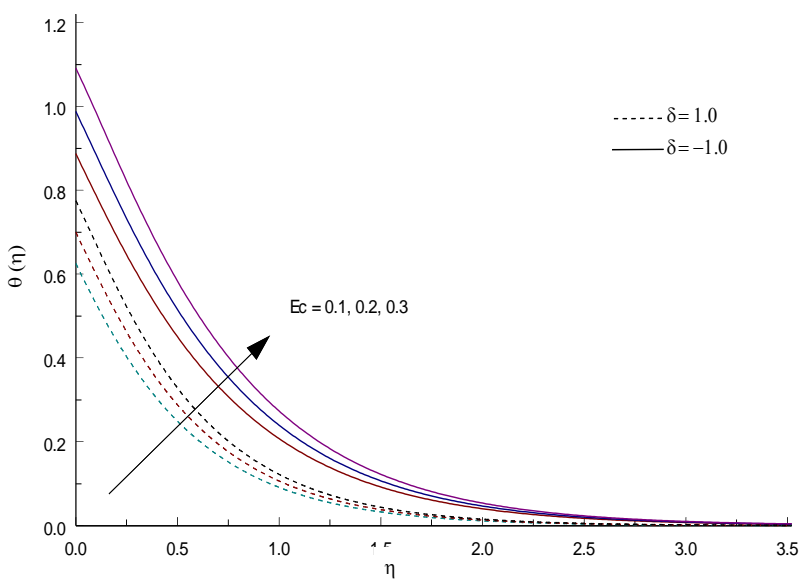

Fig. 9 Temperature distribution $\theta(\eta)$ with $\eta$ for several values of $E c$.

In addition, Figure 8 illustrates the influence of thermal radiation parameters $R_{d}$ in both shrinking/stretching sheets on the temperature distribution. With the thermal radiation at $R_{d}=$ $0.05,0.1$, and 0.2 , the flow was noticed that the temperature enhances with rise of thermal radiation parameter in both shrinking and stretching sheets.

Dimensionless temperature distribution for several values of viscous dissipation that is Eckert 
number $E c=0.1,0.2$, and 0.3 are plotted in Figure 9. The non dimensional temperature enhances with an increase in the Eckert number, viscous dissipation $E c$ for both shrinking/stretching cases and also due to the action of viscous heating as shown in this figure 9 .

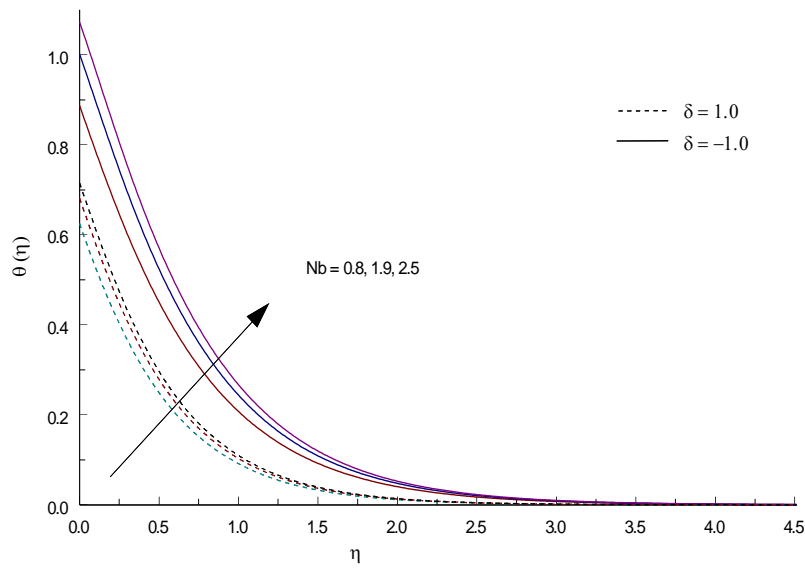

Fig. 10 Temperature distribution $\theta(\eta)$ with $\eta$ for several values of $N b$.

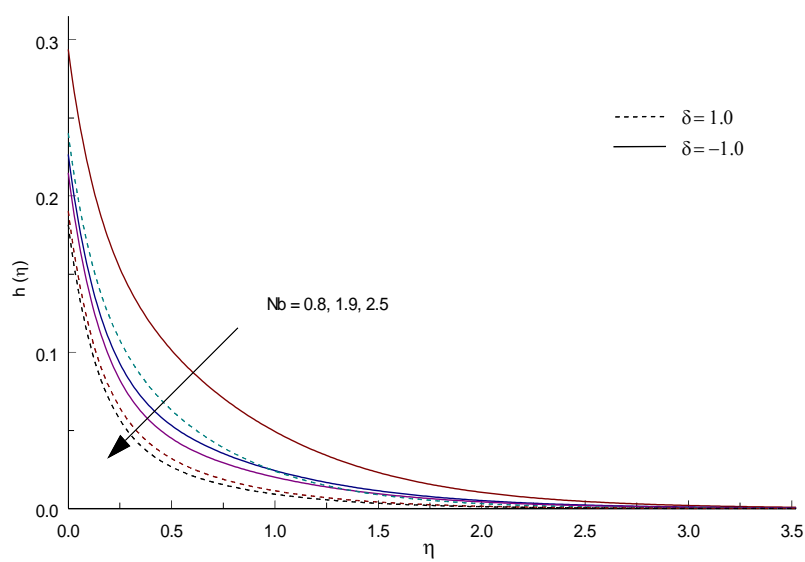

Fig. 11 Variation of concentration $h(\eta)$ with $\eta$ for several values of $N b$

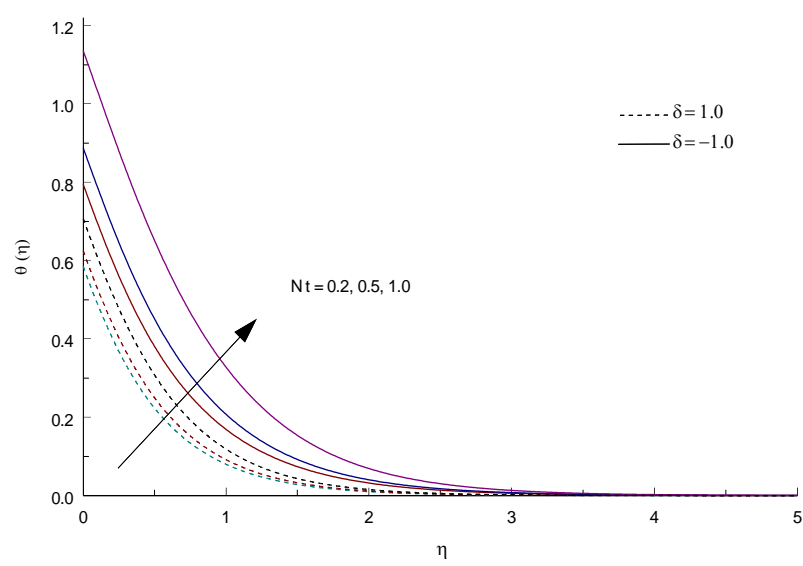

Fig. 12 Temperature distribution $\theta(\eta)$ with $\eta$ for several values of $N t$

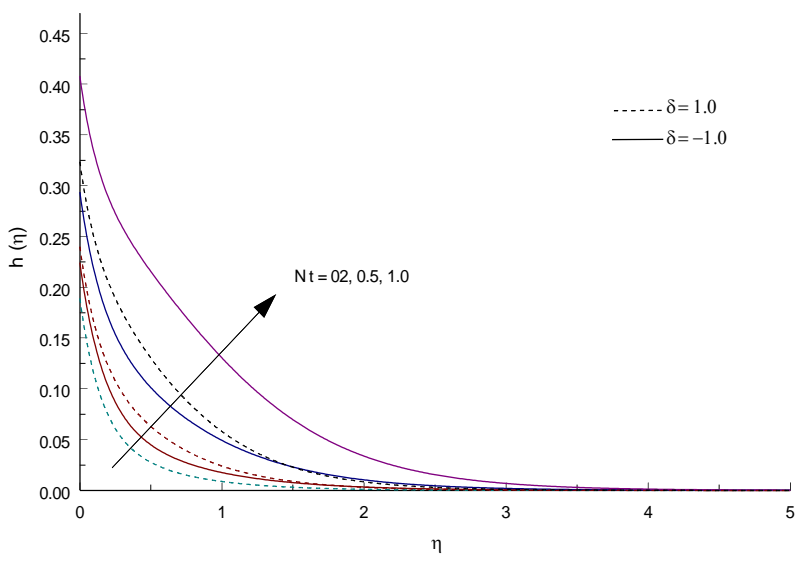

Fig. 13 Variation of concentration $h(\eta)$ with $\eta$ for several values of $N t$.

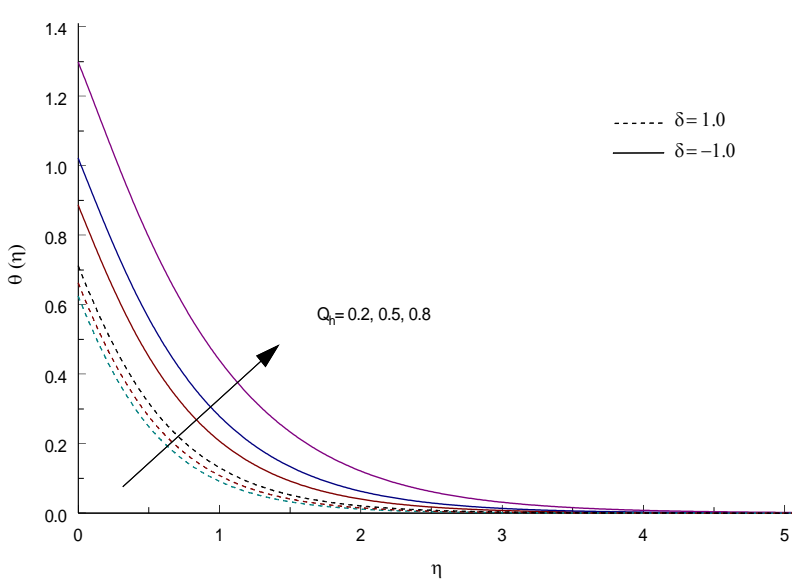

Fig. 14 Temperature distribution $\theta(\eta)$ with $\eta$ for several values of $Q_{h}$.

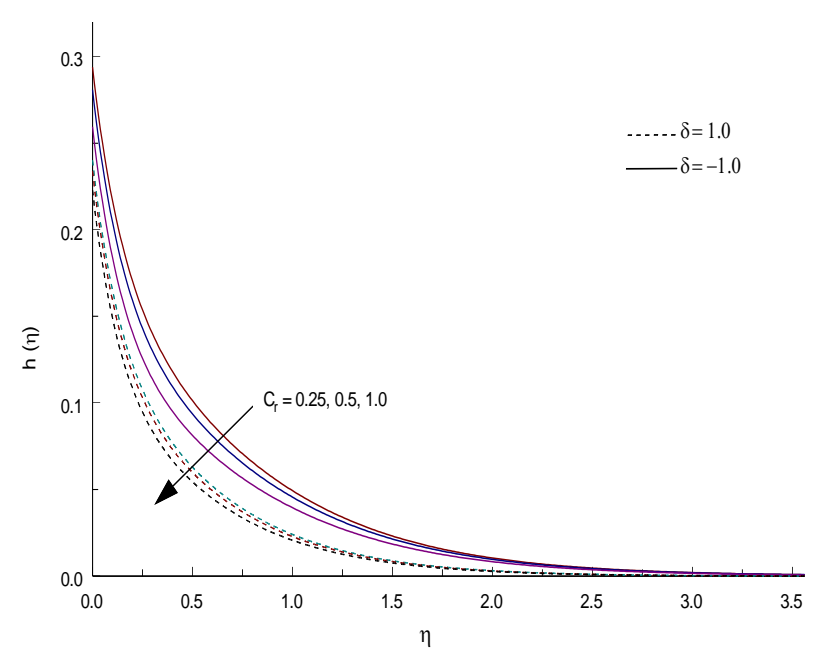

Fig. 15 Variation of concentration $h(\eta)$ with $\eta$ for several values of $C_{r}$.

Figure 10 show that the Brownian motion parameter $\mathrm{Nb}$ effects on dimensionless temperature distribution $\theta(\eta)$ for shrinking/stretching sheet cases. It is found that the thermal boundary layer 
thickness and the temperature enhances as Brownian motion parameter $\mathrm{Nb}$ for both cases. Figure 11 reveals the concentration profile $h(\eta)$ for several values of Brownian motion parameter $N b=0.8,1.9$, and 2.5 for both shrinking/stretching cases. Based on the graph, as Brownian motion parameter rises, the concentration distribution decreases for both cases. The concentration boundary layer thickness becomes thinner for larger values of the Brownian motion parameter.

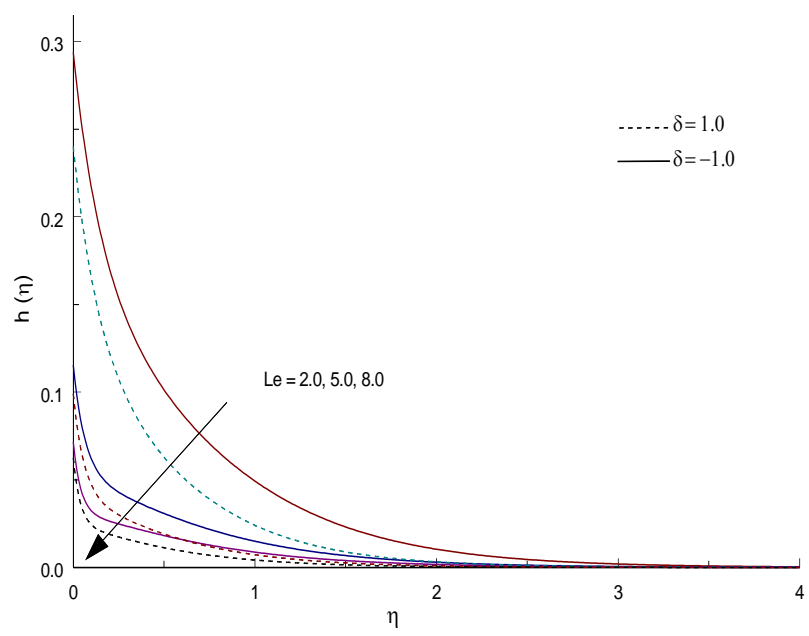

Fig. 16 Variation of concentration $h(\eta)$ with $\eta$ for several values of $L e$.

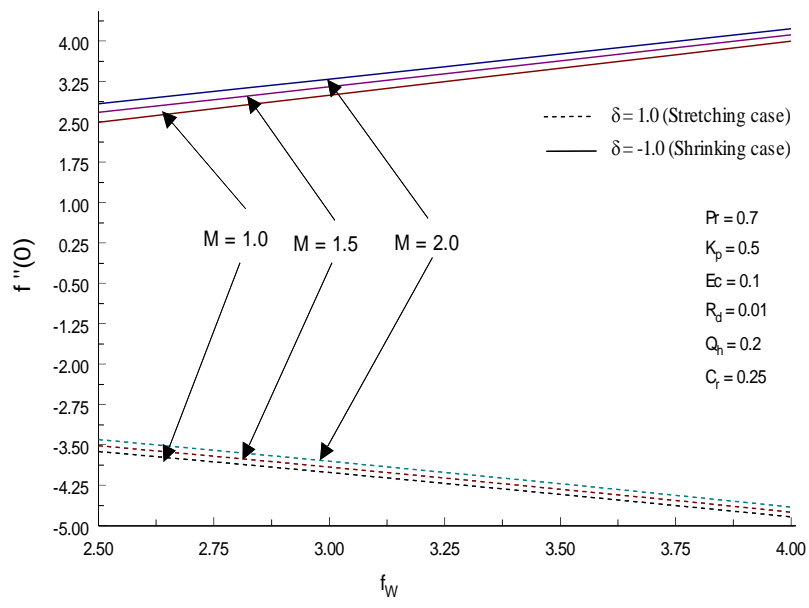

Fig. 17 Effects of $f_{w}$ on the skin friction for several values of $M$ with $\delta=-1$ and $\delta=1$

Figure 12 and 13 illustrated the dimensionless temperature and concentration profiles for various value of thermophoresis parameter $N t=0.2,0.5$, and 1.0 for both shrinking and stretching cases. It can be seen that the rising values of thermophoresis parameter $N t$ resulted the temperature and concentration increase for both cases. Also it is the ratio of the nanoparticle distribution to the thermal distribution in the nanofluid.

Figure 14 represents the influence of heat generation parameter $Q_{h}$ on the temperature distribution for both shrinking and stretching sheet cases with suction at $f_{w}=3.0$. Due to the presence of heat generation for, it is evident that there is a rise in the thermal state of the fluid. It is also noticed that the heat energy is created in thermal physical aspect that causes the temperature.

Figure 15 shows the variation of concentration profile for several values of chemical reaction parameter $C_{r}$ for both shrinking and stretching cases. It is seen that, a diminution in the concentration profile accompanies a rise in chemical reaction parameter. The variation of concentration profile for different values of Lewis number $L e$ for both shrinking/stretching cases is depicted in Figure 16. It is evident that an increase in Lewis number effects in decline in the concentration profile for both cases. The higher values of Lewis number $(L e=2.0,5.0,8.0)$ create the lower molecular diffusivity.

The variation of skin friction coefficient $f^{\prime \prime}(0)$ with magnetic interaction parameter $M$ and suction parameter $f_{w}$ are portrayed in Figure 17. From this figure, we can seen that, the skin friction enhances for both $M$ and $f_{w}$ for shrinking case and decrease the skin friction with increasing the values of $M$ and $f_{w}$ for stretching case. The solutions can also be checked from tables 2, 3, and 4. The numerical accuracy, the values of $f^{\prime \prime}(0), \theta(0)$, and $h(0)$ by the present method are compared with the results of Ghosh and Mukhopadhyay [24] in Table 1 without $M, K_{p}, R_{d}, E c, Q_{h}$, and $C_{r}$. Thus, we are very much confident that the current results are precise.

These tables 2, 3, and 4 incorporates the values of velocity profile at the wall $f^{\prime \prime}(0)$, wall thermal energy $\theta(0)$, and nanoparticle concentration at the wall $h(0)$ for different values of physical parameters with shrinking $(\delta=-1)$ and stretching $(\delta=1)$ sheets. 
WSEAS TRANSACTIONS on APPLIED and THEORETICAL MECHANICS

Table 1.

The comparison of values of $f^{\prime \prime}(0), \theta(0)$, and $h(0)$ in the absence of $M, K_{p}, R_{d}, E c, Q_{h}$, and $C_{r}$ with $\operatorname{Pr}=0.7, f_{w}=3.0, L e=1.3 N t=0.5$ for several values of $N_{b}$ when $\delta=-1$

\begin{tabular}{c|c|c|c|c|c|c}
\hline \hline \multirow{2}{*}{$N_{b}$} & \multicolumn{3}{|c|}{ Ghosh and Mukhopadhyay } & \multicolumn{3}{c}{ Present study } \\
& $f^{\prime \prime}(0)$ & $\theta(0)$ & $h(0)$ & $f^{\prime \prime}(0)$ & $\theta(0)$ & $h(0)$ \\
\cline { 2 - 7 } & & & & & & \\
\hline \hline $\mathbf{0 . 5}$ & 2.39082 & 0.656851 & 0.450768 & 2.39081 & 0.65612 & 0.450981 \\
\hline $\mathbf{1 . 0}$ & --- & 0.778270 & 0.631902 & 2.39081 & 0.77792 & 0.63210 \\
\hline $\mathbf{1 . 5}$ & --- & 0.966258 & 0.815432 & 2.39081 & 0.96619 & 0.81529 \\
\hline \hline
\end{tabular}

Table 2.

Numerically calculated Values of $f^{\prime \prime}(0), \theta(0)$, and $h(0)$ for several values of $M, K_{p}$, and $f_{w}$ with $\operatorname{Pr}=0.7, N b=0.8, N t=0.5, R d=0.05$

\begin{tabular}{ccc|cc|cc|cc}
\hline \hline$M$ & \multirow{2}{*}{$K_{p}$} & $f_{w}$ & \multicolumn{2}{|c|}{$f^{\prime \prime}(0)$} & \multicolumn{2}{|c|}{$\theta(0)$} & \multicolumn{2}{c}{$h(0)$} \\
& & & $\delta=-1$ & $\delta=1$ & $\delta=-1$ & $\delta=1$ & $\delta=-1$ & $\delta=1$ \\
\hline \hline $\mathbf{1 . 0}$ & $\mathbf{0 . 5}$ & $\mathbf{3 . 0}$ & 2.99590 & -3.80028 & 0.88792 & 0.62523 & 0.29388 & 0.24004 \\
$\mathbf{2 . 0}$ & & & 3.29431 & -4.01011 & 0.89024 & 0.63859 & 0.29178 & 0.24052 \\
$\mathbf{3 . 0}$ & & & 3.55108 & -4.20335 & 0.89368 & 0.64699 & 0.29018 & 0.24093 \\
$\mathbf{5 . 0}$ & & & 3.98797 & -4.55276 & 0.90254 & 0.66562 & 0.28769 & 0.24162 \\
\hline $\mathbf{1 . 0}$ & $\mathbf{0 . 5}$ & $\mathbf{3 . 0}$ & 2.99590 & -3.80028 & 0.88792 & 0.62523 & 0.29388 & 0.24004 \\
& $\mathbf{2 . 5}$ & & 3.55108 & -4.20335 & 0.87781 & 0.63803 & 0.29020 & 0.24105 \\
& $\mathbf{4 . 5}$ & & 3.98797 & -4.55276 & 0.87459 & 0.64884 & 0.28778 & 0.24184 \\
\hline $\mathbf{1 . 0}$ & $\mathbf{0 . 5}$ & $\mathbf{3 . 0}$ & 2.99590 & -3.80028 & 0.88792 & 0.62523 & 0.29388 & 0.24004 \\
& & $\mathbf{3 . 5}$ & 3.49734 & -4.21907 & 0.68428 & 0.54039 & 0.24647 & 0.21154 \\
& & $\mathbf{4 . 0}$ & 3.99818 & -4.65104 & 0.56537 & 0.47668 & 0.21262 & 0.18870 \\
\hline \hline
\end{tabular}

Table 3.

Numerically calculated Values of $f^{\prime \prime}(0), \theta(0)$, and $h(0)$ for several values of $\operatorname{Pr}, R_{d}, Q_{h}$ and $E c$

\begin{tabular}{cccc|cc|cc|cc}
\hline \hline $\operatorname{Pr}$ & $R_{d}$ & $E c$ & $Q_{h}$ & \multicolumn{2}{c|}{$f^{\prime \prime}(0)$} & \multicolumn{2}{c|}{$\theta(0)$} & \multicolumn{2}{c}{$h(0)$} \\
& & & & $\delta=-1$ & $\delta=1$ & $\delta=-1$ & $\delta=1$ & $\delta=-1$ & $\delta=1$ \\
\hline \hline $\mathbf{0 . 7}$ & $\mathbf{0 . 0 5}$ & $\mathbf{0 . 1}$ & $\mathbf{0 . 2}$ & 2.99590 & -3.80028 & 0.88792 & 0.62523 & 0.29388 & 0.24004 \\
$\mathbf{1 . 2}$ & & & & & & 0.54399 & 0.41256 & 0.29536 & 0.24217 \\
$\mathbf{2 . 0}$ & & & & & & 0.36032 & 0.29166 & 0.29824 & 0.24377 \\
\hline $\mathbf{0 . 7}$ & $\mathbf{0 . 0 5}$ & $\mathbf{0 . 1}$ & $\mathbf{0 . 2}$ & 2.99590 & -3.80028 & 0.88792 & 0.62523 & 0.29388 & 0.24004 \\
& $\mathbf{0 . 1}$ & & & & & 0.94149 & 0.65720 & 0.29355 & 0.23976 \\
& $\mathbf{0 . 2}$ & & & & & 1.05034 & 0.72132 & 0.29284 & 0.23923 \\
\hline $\mathbf{0 . 7}$ & $\mathbf{0 . 0 5}$ & $\mathbf{0 . 1}$ & $\mathbf{0 . 2}$ & 2.99590 & -3.80028 & 0.88792 & 0.62523 & 0.29388 & 0.24004 \\
& & $\mathbf{0 . 2}$ & & & & 0.98826 & 0.69963 & 0.29391 & 0.23900 \\
& & $\mathbf{0 . 3}$ & & & & 1.09165 & 0.77524 & 0.29392 & 0.23795 \\
\hline $\mathbf{0 . 7}$ & $\mathbf{0 . 0 5}$ & $\mathbf{0 . 1}$ & $\mathbf{0 . 2}$ & 2.99590 & -3.80028 & 0.88792 & 0.62523 & 0.29388 & 0.24004 \\
& & & $\mathbf{0 . 5}$ & & & 1.02255 & 0.66326 & 0.29331 & 0.23966 \\
& & & $\mathbf{0 . 8}$ & & & 1.29928 & 0.71251 & 0.29194 & 0.23919 \\
\hline \hline
\end{tabular}


Table 4.

Numerically calculated Values of $f^{\prime \prime}(0), \theta(0)$, and $h(0)$ for several values of $C_{r}, L e, N b$ and $N t$ with $M=1.0, \operatorname{Pr}=0.7, R_{d}=0.05, f_{w}=3.0$

\begin{tabular}{cccc|cc|cccc}
\hline \hline$C_{r}$ & $L e$ & $N b$ & $N t$ & \multicolumn{2}{|c|}{$f^{\prime \prime}(0)$} & \multicolumn{2}{|c|}{$\theta(0)$} & \multicolumn{2}{c}{$h(0)$} \\
& & & & $\delta=-1$ & $\delta=1$ & $\delta=-1$ & $\delta=1$ & $\delta=-1$ & $\delta=1$ \\
\hline \hline $\mathbf{0 . 2 5}$ & $\mathbf{2 . 0}$ & $\mathbf{0 . 8}$ & $\mathbf{0 . 5}$ & 2.99590 & -3.80028 & 0.88792 & 0.62523 & 0.29388 & 0.24004 \\
$\mathbf{0 . 5}$ & & & & & & 0.88458 & 0.62439 & 0.28083 & 0.23384 \\
$\mathbf{1 . 0}$ & & & & & & 0.87909 & 0.62289 & 0.25945 & 0.22289 \\
\hline $\mathbf{0 . 2 5}$ & $\mathbf{2 . 0}$ & $\mathbf{0 . 8}$ & $\mathbf{0 . 5}$ & 2.99590 & -3.80028 & 0.88792 & 0.62523 & 0.29388 & 0.24004 \\
& $\mathbf{5 . 0}$ & & & & & 0.83340 & 0.60053 & 0.11541 & 0.09885 \\
& $\mathbf{8 . 0}$ & & & & & 0.81885 & 0.59306 & 0.07162 & 0.06240 \\
\hline $\mathbf{0 . 2 5}$ & $\mathbf{2 . 0}$ & $\mathbf{0 . 8}$ & $\mathbf{0 . 5}$ & 2.99590 & -3.80028 & 0.88792 & 0.62523 & 0.29388 & 0.24004 \\
& & $\mathbf{1 . 9}$ & & & & 1.00225 & 0.68177 & 0.22667 & 0.19027 \\
& & $\mathbf{2 . 5}$ & & & & 1.07313 & 0.71522 & 0.21493 & 0.18157 \\
\hline $\mathbf{0 . 2 5}$ & $\mathbf{2 . 0}$ & $\mathbf{0 . 8}$ & $\mathbf{0 . 2}$ & 2.99590 & -3.80028 & 0.79519 & 0.58551 & 0.22437 & 0.18899 \\
& & & $\mathbf{0 . 5}$ & & & 0.88792 & 0.62533 & 0.29388 & 0.24004 \\
& & & $\mathbf{1 . 0}$ & & & 1.13603 & 0.70748 & 0.40805 & 0.32365 \\
\hline \hline
\end{tabular}

\section{Conclusion}

In this article, the numerical result of twodimensional, laminar, incompressible, nonlinear hydromagnetic flow and heat transfer of radiative nanofluid over an exponentially shrinking/stretching porous sheet in the presence of viscous, Ohmic dissipations and heat generation has been studied. Brownian motion, thermophoresis, chemical reaction, and permeability also taken into account. The governing equations were transformed into an ordinary differential equation and solved numerically A parametric study is performed to illustrate the influence of tested physical parameters. The solutions concerning to the present research indicate that

- For exponentially shrinking and stretching sheets the rotational generation in larger compared to that for the liner shrinking or stretching sheet.

- Velocity of the fluid increases for shrinking sheet and velocity of the fluid decreases for stretching sheet with increasing magnetic field and permeability for the fixed value of suction parameter.

- In both shrinking and stretching sheets, the presence of magnetic field, thermal radiation, Brownian motion, and heat generation increases the temperature but decreases the concentration profile.

- An enhancement of Lewis number Le reduces the temperature and also concentration profile for both shrinking and stretching sheets.

- Due to the effect of Prandtl number, temperature is declined and hence the thermal boundary layer thickness becomes thinner. But, the concentration accelerates with enhancing Prandtl number.

- The magnitude of the skin friction increases, with rising values of magnetic interaction parameter $M$ and suction parameter $f_{w}$ for shrinking sheet and decreases the skin friction with increasing values of $M$ and $f_{w}$.

- The energy dissipation (being indicated by viscous dissipation) due to Eckert number $E c$ has the tendency to thicken the thermal boundary layer, so as to raise the nondimensional temperature.

- With an enhance in parameter $N t$, the dimensionless temperature and concentration increases for the shrinking and starching sheets. Dimensionless temperature and nanoparticle concentration at the wall $[\theta(0)$ and $\mathrm{h}(0)]$ are larger for larger values of thermophoresis $N t$. 
References:

[1] Crane LJ. Flow past a stretching plate. $J$. Appl. Math. Phys. (ZAMP). Vol.21, 1970, pp.645-647.

[2] Kumaran V, Ramanaiah G. A note on the flow over a stretching sheet. Acta. Mech. Vol.116, No.(1-4), 1996, pp. 229-233.

[3] Cortell R. Viscous flow and heat transfer over a nonlinearly stretching sheet. Applied Mathematics and Computation. Vol.184, No.2, pp.864-873.

[4] Hayat T, Abbas Z, Javed T. Mixed convection flow of a micropolar fluid over a non-linearly stretching sheet. Physics letters A. Vol.372, No.5, 2008, pp.637-647.

[5] Kishan N, Kalyani C, Chenna Krishna Reddy M. MHD Boundary Layer Flow of a Nanofluid over an Exponentially Permeable Stretching Sheet with radiation and heat Source/Sink. Transp. Phenom. Nano Micro Scales. Vol.4, No.1, 2016, pp. 44-51.

[6] Wang CY, Stagnation point flow towards a shrinking sheet. Int. J. Non-Linear Mech. Vol.43, 2008, pp.377-382.

[7] Fang T. Boundary layer flow over a shrinking sheet with power-law velocity. International Journal of Heat and Mass Transfer. Vol.51, No.(25-26), 2008, pp.58385843.

[8] Bhattacharyya K. Effects of heat source/sink on MHD flow and heat transfer over a shrinking sheet with mass suction. Chemical Engineering Research Bulletin. Vol.15, No.1, 2011, pp.12-17.

[9] Jusoh R, Nazar R, Pop I. Magnetohydrodynamic boundary layer flow and heat transfer of nanofluids past a bidirectional exponential permeable stretching/shrinking sheet with viscous dissipation effect. Journal of Heat Transfer. Vol.141, No.1, 2019, 012406.

[10] Choi SUS. Enhancing Thermal Conductivity of Fluids with Nanoparticles. Proceedings of the ASME International Mechanical Engineering Congress and Exposition. Vol.66, 1995, pp.99-105.

[11] Buongiorno J, Hu L, Masschusetts Institute of Technology. 2009.

[12] Sheikholeslami M, Abelman S, Ganji DD. Numerical simulation of MHD nanofluid flow and heat transfer considering viscous dissipation. International Journal of Heat and Mass Transfer. Vol.79, 2014, pp.212222.

[13] Dehghani MS, Toghraie D, Mehmandoust B. Effect of MHD on the flow and heat transfer characteristics of nanofluid in a grooved channel with internal heat generation. International Journal of Numerical Methods for Heat \& Fluid Flow. Vol.29, No.4, 2019, pp.1403-1431.

[14] Noor NF, Kechil SA, Hashim I. Simple nonperturbative solution for MHD viscous flow due to a shrinking sheet. Communications in Nonlinear Science and Numerical Simulation. Vol.15, No.2, 2010, pp.144-148.

[15] Yian LY, Ishak A, Pop I. MHD stagnation point flow with suction towards a shrinking sheet. Sains Malaysiana. Vol.40, No.10, 2011, pp.1179-1186.

[16] Nayak MK, Akbar NS, Pandey VS, Khan $\mathrm{ZH}$, Tripathi D. 3D free convective MHD flow of nanofluid over permeable linear stretching sheet with thermal radiation. Powder technology. Vol.315, 2017, pp.205215.

[17] Murugesan T, Kumar MD. Effects of thermal radiation and heat generation on hydromagnetic flow of nanofluid over an exponentially stretching sheet in a porous medium with viscous dissipation. World Scientific News. Vol. 128, No.2, 2019, pp.130-147.

[18] Cortell R. Effects of viscous dissipation and radiation on the thermal boundary layer over a nonlinearly stretching sheet. Physics Letters A. Vol.372, No.5, 2008, pp.631-636.

[19] Chamkha AJ, Dogonchi AS, Ganji DD. Magneto-hydrodynamic flow and heat transfer of a hybrid nanofluid in a rotating system among two surfaces in the presence of thermal radiation and Joule heating. AIP Advances. Vol.9, No.2, 2019, 025103.

[20] Awais M, Hayat T, Irum S, Alsaedi A. Heat generation/absorption effects in a boundary layer stretched flow of Maxwell nanofluid: Analytic and numeric solutions. PloS one. Vol.10, No.6, 2015, e0129814.

[21] Mishra A, Kumar M. Ohmic-Viscous Dissipation and Heat Generation/Absorption Effects on MHD Nanofluid Flow Over a Stretching Cylinder with Suction/Injection. In Advanced Computing and Communication Technologies. 2019, pp.45-55. Springer, Singapore. 
[22] Thumma T, Mishra SR, Shamshuddin MD. Effect of Heat Generation and Viscous Dissipation on MHD 3D Casson Nanofluid Flow Past an Impermeable Stretching Sheet. In Numerical Heat Transfer and Fluid Flow. 2019, pp.575-585. Springer, Singapore.

[23] Hossain MA, Alim MA, Rees DAS. The effect of radiation on free convection from a porous vertical plate. International Journal of Heat and Mass Transfer. Vol.42, No.1, 1999, pp.181-191.

[24] Ghosh, S, Mukhopadhyay, S. Flow and heat transfer of nanofluid over an exponentially shrinking porous sheet with heat and mass fluxes. Propulsion and Power Research. Vol.7, No.3, 2018, pp.268-275.

\section{Creative Commons Attribution License 4.0 (Attribution 4.0 International, CC BY 4.0)}

This article is published under the terms of the Creative Commons Attribution License 4.0

https://creativecommons.org/licenses/by/4.0/deed.en_US 